Revista Destaques Acadêmicos, Lajeado, v. 13, n. 2, 2021. ISSN 2176-3070

DOI: http://dx.doi.org/10.22410/issn.2176-3070.v13i2a2021.2934

http://www.univates.br/revistas

\title{
PERTENCIMENTOS, IDENTIDADES E NARRATIVAS - O CASO DE PRECIOSA E A PESQUISA COM OS COTIDIANOS
}

\author{
Elaine Sotero ${ }^{1}$, Marco Aurélio Correa ${ }^{2}$, Tatiana Reis ${ }^{3}$
}

Resumo: O presente texto pretende apresentar reflexões sobre as pesquisas com os cotidianos (ALVES, 2001) e como estas redes educativas se tecem rizomaticamente com demais conceitos - como personagens conceituais (DELEUZE, GUATTARI, 1992); pertencimento (SOUSA, 2010) e identidades -, para pensar de que maneiras se criam currículos escolares. Conversando com o filme Preciosa (2009) como um filme dos movimentos dos cinemas negros (CARVALHO, 2005) encontramos algumas oportunidades para tecer currículos que debatam as questões raciais, como define a lei 10639/03 (BRASIL, 2003), mas indo além do seu caráter de obrigatoriedade. A experiência de Preciosa nos permite pensar como as subjetividades da questão racial estão presentes em nossos cotidianos, o que permite tornar tal discussão ainda mais contundente para os currículos escolares.

Palavras chave: Pesquisas com os cotidianos; Redes educativas; Cinemas negros; Currículos.

\section{INTRODUZINDO AS PESQUISAS COM OS COTIDIANOS, RIZOMAS E PERSONAGENS CONCEITUAIS}

Para iniciar nossas considerações precisamos compreender o questionamento teórico que trazemos para discussão. Reconhecendo que a sociedade em que vivemos atualmente é formada por paradigmas que tem origens na época conhecida como Modernidade, onde as ideias em ciências

implantaram a compreensão de que o conhecimento se constrói com as pesquisas desenvolvidas pelos cientistas dentro da metáfora da

1 Mestranda em Educação pelo Programa de Pós Graduação em Educação da Universidade do Estado do Rio de Janeiro - UERJ.

2 Mestrando em Educação pelo Programa de Pós Graduação em Educação da Universidade do Estado do Rio de Janeiro - UERJ.

3 Mestranda em Educação pelo Programa de Pós Graduação em Educação da Universidade do Estado do Rio de Janeiro - UERJ. 
árvore (Lefebvre, 1983), vimos que a criação dos conhecimentos nos cotidianos era feita em redes, segundo esse mesmo autor. Desse modo, nas pesquisas com os cotidianos, adotamos a ideia de que os conhecimentossignificações são tecidos. Percebemos, então, que ao mesmo tempo em que tecemos conhecimentos, tecemos significações para os mesmos que os explicam e nos dizem do valor que têm para o viver cotidiano. (ALVES, FERRAÇO e SOARES, 2017, p. 11)

Desta forma, as pesquisas com os cotidianos se propõem a pensar com os 'praticantespensantes' do cotidiano e as tessituras de experiências, memórias, afetos e várias outras expressões que se compõem em redes educativas (ALVES, 2001). Esta maneira de se pensar em redes é uma forma de ir além das delimitações da Modernidade. A ciência moderna por desconsiderar os 'conhecimentossiginifcações' criados nos cotidianos, os limitando ao senso comum, faz com que somente os valores certificados e estabelecidos hegemonicamente pela ciência sejam vistos como verdade.

Rizomaticamente, os 'praticantespensantes' vão organizando táticas e fazendo usos (CERTEAU, 1998) que subvertem a ideia hegemônica de Modernidade. Os rizomas são, como a botânica explica, microfilamentos subterrâneos que se tocam, se encontram e se tecem, compondo uma vasta rede de ações incalculáveis e imprevisíveis para quem vê de cima. Deleuze e Guattari em seu Mil platôs - capitalismo e esquizofrenia (1995), definem esse conceito:

Um rizoma não começa nem conclui, ele se encontra sempre no meio, entre as coisas, inter-ser, intermezzo. A árvore é filiação, mas o rizoma é aliança, unicamente aliança. A árvore impõe o verbo "ser", mas o rizoma tem como tecido a conjunção "e... e... e..." Há nesta conjunção força suficiente para sacudir e desenraizar o verbo ser. [...] Entre as coisas não designa uma correlação localizável que vai de uma para outra e reciprocamente, mas uma direção perpendicular, um movimento transversal que as carrega uma e outra, riacho sem início nem fim, que rói suas duas margens e adquire velocidade no meio. (p. 36)

Assim com estas considerações percebemos que os saberes são tecidos constantemente nos cotidianos. Abrangendo a forma de encarar a complexidade deste problema descobrimos um mundo todo de possibilidades. Esta é uma atitude de subversão, que inverte os valores estabelecidos pela modernidade, ampliando as formas de percepção de uma maneira plena. São os acontecimentos dos cotidianos que nos mostram que a vida não é fria, calculável e previsível, são as multiplicidades dos acontecimentos que nos mostram a sua potência e complexibilidade (ALVES, 2001).

Com o problema evidenciado e as táticas organizadas podemos pensar em práticas que possíveis para alterar esse sistema. Acreditamos nas pesquisas com os cotidianos que nossas experiências imagéticas e sonoras são marcantes 
para nossa formação pessoal e identitária (ALVES, CALDAS e ROSA, 2015). Desta forma, um artefato cultural, que pode parecer simples ou um mero entretenimento, se torna uma potente criação para se pensar nossas criações cotidianas. Encaramos assim filmes como personagens conceituais (DELEUZE, GUATTARI, 1992), aqueles que são intercessores para nosso pensamento e para nosso discurso. Alves, elucida bem esta ideia

Os personagens conceituais são, assim, aquelas figuras, argumentos ou artefatos que entram como o outro - aquele com que se 'conversa' e que permanece presente muito tempo para que possamos acumular as ideias necessárias ao desenvolvimento de conhecimentos e a compreensão de significações nas pesquisas que desenvolvemos. Esses personagens conceituais aí têm que estar, para que o pensamento se desenvolva, para que novos conhecimentos apareçam, para que lógicas se estabeleçam. (ALVES, 2011, p.13).

Para o desenvolvimento de nosso posicionamento neste texto iremos fazer uso do filme Preciosa - Uma História de Esperança (2009) como um personagem conceitual para pensarmos a educação, currículos e cotidianos escolares.

Figura 1 - Pôster do filme Preciosa

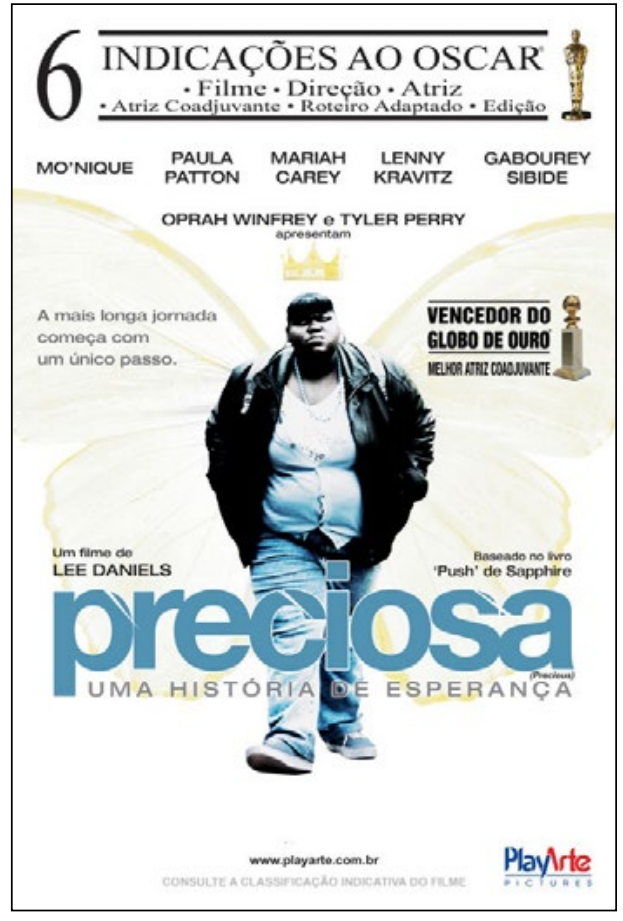


Considerando a ideia de redes educativas, os acontecimentos dos cotidianos dos 'praticantespensantes' da escola, são potências que definem e influenciam os cotidianos nas destas. Entendemos 'praticantespensantes' das escolas também não somente os professores, os educandos, os funcionários, as famílias. Todos participantes dos cotidianos escolares são sujeitos de potência para a prática da educação. Todas as subjetividades destes 'praticantespensantes' estão atuando nos acontecimentos dos cotidianos escolares.

Desta forma, o mero ato de assistir um filme nos faz pensar sobre a educação de uma maneira ampla e crítica. Apesar do filme não representar a própria realidade, nem uma fidedigna representação dela, o cinema é uma criação humana que pode nos fazer pensar sobre nossos cotidianos.

\section{CONTEXTO DO FILME PRECIOSA - PENSANDO EM UM CINEMA NEGRO}

O cinema, considerando suas muitas potências, não pode ser pensado somente a partir de seu produto final: o filme. O processo criativo das imagens, narrativas e sons de um filme é amplo e potente em diversas escalas. Este processo abrange desde a habilidade artística do sujeito que assina a direção de um filme, até as subjetividades do sujeito mais distante do processo criativo, como um figurante. Além de ser uma expressão artística coletiva - dependendo de diferentes profissionais como, roteiristas, fotógrafos, atores e eletricistas - o cinema é uma obra plural, por estar inserido em uma sociedade ampla e diversa. Apesar do cinema não ser uma mera representação do real, tentando simular um senso de realidade, o cinema produz a própria realidade, um filme nada mais é do que uma criação do real a partir das contribuições de diferentes sujeitos.

Somente com estas divagações acerca do cinema já podemos perceber o quão relacionado ele está à ideia de tessitura em redes. São todas as experiências, vivências, memórias e outros elementos das subjetividades que fazem o cinema ser uma criação humana tão plural e potente. Atravessando a tela e pensando no outro lado da exibição, o público, o cinema atua de uma forma bem ampla, pois são as mesmas características subjetivas de um expectador que fazem o cinema nos afetar e marcar de diferentes maneiras. A dinâmica dos afetos e das percepções fazem com que o cinema se torne um potente artefato na criação de significações naqueles que interagem com esta forma de arte.

Com esta característica o cinema se tornou no decorrer da história um artefato cultural utilizado para a disseminação de um discurso político. Discursos estes que poderiam servir para diferentes perspectivas políticas, como vemos na história da indústria hollywoodiana e do cinema socialista soviético (GUERON, 2011). Porém, da mesma forma que existem diferentes gêneros e temáticas presentes no cinema, existem diferentes discursos representados na 
história do mesmo, e nem sempre eles se demonstram na maneira hegemônica, e lucrativa, de se fazer filmes.

Além do discurso político hegemônico no cinema - entendendo hegemonia como dominação econômica, política e cultural - existem cinemas que propõem rupturas às hegemonias, principalmente as consolidadas no ocidente. Para os processos de dominação ocidental:

Desde o Renascimento, a modernidade ocidental coloca o homem europeu no centro do seu modelo, primeiro como "civilizado" (frente aos bárbaros ou selvagens), depois como homo economicus, essa "descoberta" do século XVIII, destinado a se tornar paradigma antropológico universal, acompanhando idelogicamente a expansão planetária dos comerciantes, soldados e missionários cristãos. Dentro do modelo, esse homem universal é branco, cor que fornece o padrão antropológico - assim como o ouro pode ser padrão monetário - para a classificação da heterogeneidade, para a diversidade da epiderme humana e dos modos de realização simbólica. Desse monismo fenotípico decorre uma espécie de "leucocracia", queéa dominação social exercida pela "branquitude", o paradigma tradutor da divisão planetário do trabalho em classes biológicas ou étnicas. (SODRÉ, p. 99)

Analisando o contexto do filme que trazemos para a conversa no decorrer desse texto, Preciosa é um filme que pode ser relacionado a um movimento cinematográfico, o cinema negro. Os movimentos cinematográficos podem ser definidos de diversas maneiras, a partir de: pertencimentos a um 'espaçotempo'; pertencimentos a um movimento estilístico; pertencimentos a um grupo étnicocultural; pertencimentos a um discurso político e dentre outros. O cinema negro não pode ser definido somente com uma destas características, o que melhor o define é o seu posicionamento perante as dificuldades e desigualdades que os corpos e mentes negras sofrem pela hegemonia da modernidade.

No contexto brasileiro, o cinema negro "debate os conceitos em torno da consolidação hegemônica da identidade nacional brasileira empenhada em colocar o negro em posição de subalternidade e não como elemento fundamental na formação cultural do país." (OLIVEIRA, 2016, p. 1). Porém, este posicionamento político não se limita ao nosso contexto, a experiência da população negra brasileira é similar com a diáspora africana das Américas. Diversos cineastas pelo atlântico produzem filmes que questionam a situação de negras e negros em seus contextos específicos. Reforçando que as criações destes cineastas da diáspora africana são uma proposta contra hegemônica à dominação do ocidente. Gilroy (2001), no seu livro O Atlântico Negro: modernidade e dupla consciência, nos aponta:

Utilizei o modelo do Atlântico negro para identificar outras possibilidades e interpretações. As culturas do Atlântico negro 
criaram veículos de consolação através da mediação do sofrimento. Elas especificam formas estéticas e contra-estéticas e uma distinta dramaturgia da recordação que caracteristicamente separam a genealogia, da geografia, e o ato de lidar com o de pertencer. Tais culturas da consolação são significativas em si mesmas, mas também estão carregadas e contrapostas a uma sombra: a consciência oculta e dissidente de um mundo transfigurado que tem sido ritual e sistematicamente conjurado por pessoas que agem em conjunto e se abastecem com a energia fornecida por urna comunidade mais substantivamente democrática do que a raça jamais permitirá existir. Podemos encontrar prazer nesta história de resistência, mas, mais polemicamente, acho que deveríamos também estar preparados para lê-la política e filosoficamente nos momentos em que ela incorporou e manifestou críticas ao mundo tal como é. (p. 13)

Os filmes que fazem parte deste movimento afirmam a sua potência como linhas de fuga quando propõem uma ressignificação das imagens, narrativas e sons das subjetividades negras do cinema, presença essa constantemente representada nas telas de forma insuficientes ou discriminatórias. Narrativizar essas experiências e subjetividades é uma forma de superar, a dolorosa condição histórica imposta a este povo. Todos os dramas, afetos, sentimentos, alegrias e tristezas são formas de potenciar outros sujeitos a uma reviravolta as desigualdades que conhecemos. Apesar de muitas vezes doloroso, é preciso tracejar esse caminho criando outras oportunidades e possibilidades de transformação.

Preciosa - Uma história de Esperança (2009) é uma inspirada na obra literária Push (1996) da autora Sapphire adaptada e dirigida para cinema pelo diretor Lee Daniels. Daniels também realizou as obras representado as histórias de personalidades como Eugene Allen, mordomo que trabalhou quase quatro décadas na casa branca estadunidense; e Billie Holiday a icônica cantora de jazz. Todos os seus filmes apresentam uma forte crítica a realidade a sociedade americana, evidenciando as dores de pessoas negras, representações as vezes as muito delicadas dessas realidades. 
Figura 2 - Mo'Nique, que interpreta a mãe, Mary; Gabourey "Gabby" Sidibe, Preciosa; diretor Lee Daniels; e Sapphire, autora do livro em que o filme se baseou- se encontram no festival Sundance Jan. 16, 2009.

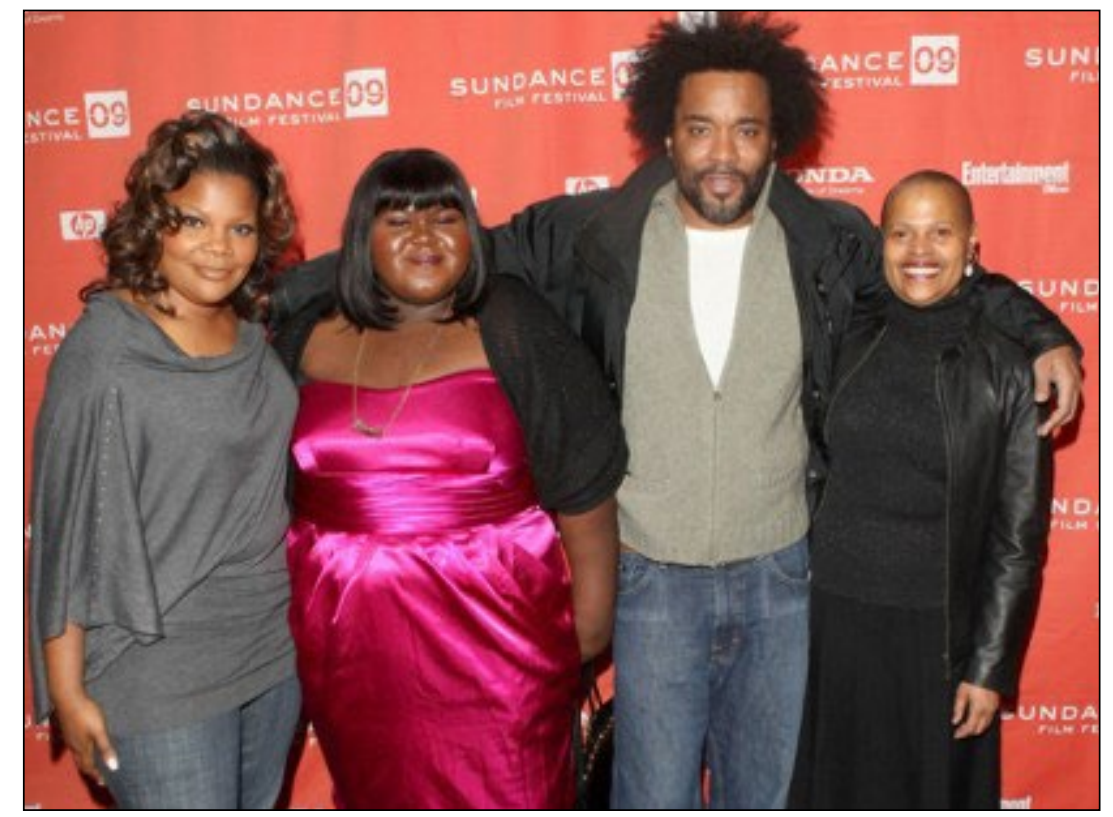

\section{CONVERSANDO COM PRECIOSA}

O filme Preciosa retrata o cotidiano turbulento e cheio de conflitos de uma jovem negra de 16 anos que não corresponde ao padrão estético de beleza. Residindo em uma região periférica dos Estados Unidos, os dramas e problemáticas que envolvem a personagem Preciosa são inúmeros indo: desde a rejeição da mãe dentro do próprio lar; abusos sexuais cometidos pelo pai; até sua falta de pertencimento a sociedade no geral, como por exemplo a escola que a mesma frequenta e a sua vizinhança.

Durante o filme o telespectador pode refletir através de temas que surgem na trama que são de extrema importância, pois estes assuntos que retratados pelas narrativas são presentes em diversas redes que se articulam em nossa sociedade. Racismo, homofobia, abusos sexuais, desigualdade social, bullying etc. são alguns dos temas que permeiam fortemente a trama. Preciosa se vê durante grande parte dos momentos cercadas por traumas e barreiras que envolvem questões que fazem parte do seu presente e do seu passado também.

Em um momento especifico a personagem se olha no espelho e diante de si vê a imagem de uma mulher loura branca e de cabelos loiros e lisos. Aquela mulher representa a mulher que a Preciosa deseja ser, ou seja, uma mulher totalmente o oposto do que a mesma é. Preciosa é negra, obesa e possui características "indesejadas" como por exemplo: nariz largo, boca grossa e 
cabelo crespo alisado. Segundo Nilma Lino Gomes vivemos em uma sociedade com "uma estrutura racista onde a cor da pele de uma pessoa infelizmente é mais determinante para o seu destino social do que o seu caráter, a sua história, a sua trajetória" $(2005$, p. 46). Se a cor da pele e os fenótipos relacionados a ela são determinantes para a trajetória social é entendível porque mulheres e homens negros tentam se adaptar a estética dominante. Podemos então nos questionar porque Preciosa deseja tanto ter aquela aparência, onde foi ensinado a ela que aquela aparência corresponde a aparência ideal? Em que momento especifico de sua vida lhe foi imposto que suas características são "feias, inaceitáveis, indesejáveis" e as daquela outra imagem-mulher são "belas, aceitáveis e desejáveis"?

Figura 3 - Preciosa olhando seu "reflexo" no espelho

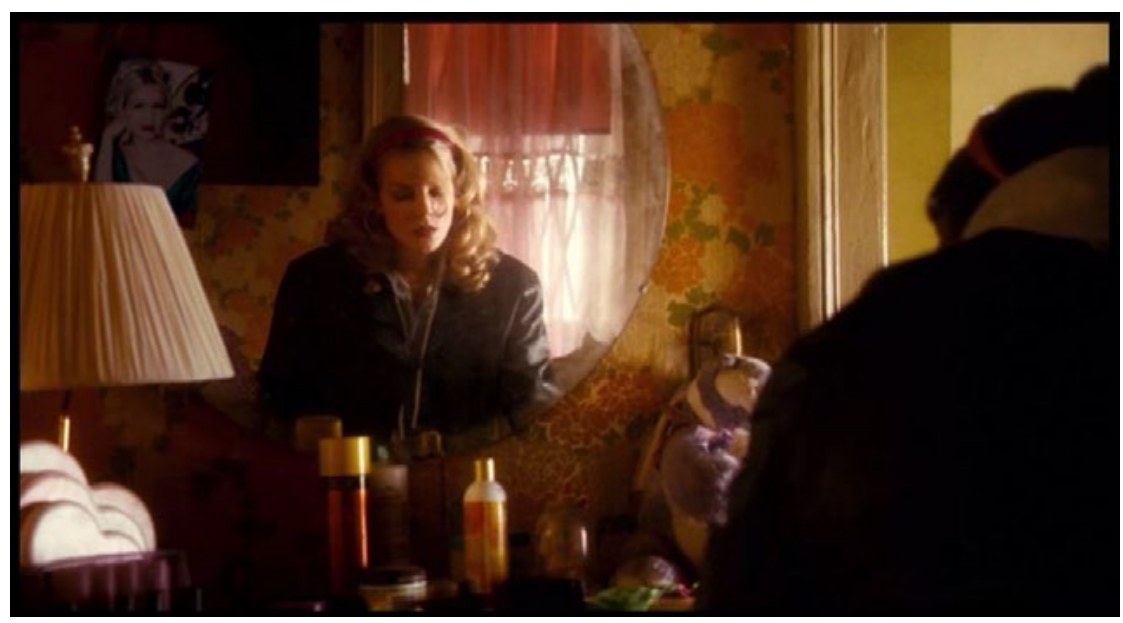

A grande questão que pode ser problematizada é que na verdade não houve um momento especifico e nem um lugar específico que essas "lições" sobre padrões de beleza lhe foram ensinadas. Elas são fruto da reprodução cotidiana de crenças comuns sobre a estética de pessoas negras. Curioso é reparar que em todos os devaneios que aparecem no decorrer do filme, onde a protagonista sonha com reconhecimento, popularidade e riqueza ela sempre é retratada do jeito que é. Talvez, sua imaginação seja um broto do seu subconsciente que a considera perfeita do jeito que é, ao invés da imagem introjetada socialmente da beleza de padrões eurocêntricos.

Giovana Xavier em criteriosa pesquisa sobre a midiatização da beleza negra na impressa negra norte-americana e brasileira nas primeiras décadas do século $X X$, percebe como negras e negros buscavam uma beleza cívica para a sua população, pensando na inserção social, econômica e política:

A ideia do civismo qualificador de uma beleza específica negra dimensiona que na cosmética afro-americana o que estava em 
jogo era construir a "feminilidade respeitável" (Wolcott, 2001:3), fabricando uma aparência suficientemente convincente do respeito e da dignidade das mulheres. Falo de mulheres que eram previamente julgadas por traços físicos que denunciavam sua descendência africana, ou seja, a pele e, não menos importante, o cabelo. Nesse sentido, as experiências de manipulação do corpo negro também revelam um intento feminino. Qual seria? Desconstruir estereótipos através da comercialização e uso de produtos criados para encontrar a tonalidade de pele e o penteado mais adequado para representar o que julgavam ser uma beleza cívica negra (2014, p. 431).

Então observando este movimento percebemos que é possível se criar uma beleza negra que esteja aliada às ideias de civilidade, sem se ater por completo a padronização estética da branquitude. Vemos um grande crescimento contemporâneo da representatividade, que alia a estética negra a comercialização e a mídia, mas mesmo distante desse discurso liberal, é possível pensar numa beleza cívica negra que esteja associada as tradições, sem se ater ao esvaziamento capitalista. Por isso é importante reconhecer as culturas e histórias africanas e afro-brasileiras, para se criar uma estética sem estar completamente alijada aos interesses do mercado.

Figura 4 - Um dos devaneios de fama da protagonista

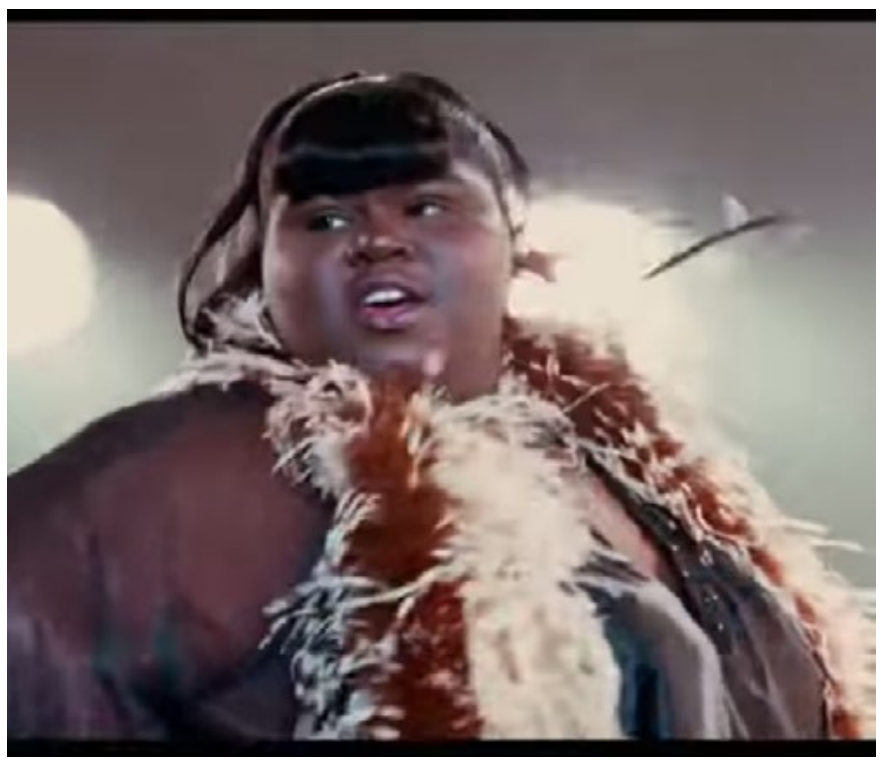

Conforme Nilda Alves nos conta, "na poesia do mestre está expressa, tanto a insignificância de cada ser individual como essa necessária condição de cada um e de todos. Somos esse acúmulo de ações e acontecimentos culturais cotidianos, insignificantes, mas formadores necessários." (ALVES, 2003, p. 62). Fazendo um diálogo com as ideias de Alves, podemos perceber que a mesma 
trata da relação de um poeta especifico com a sua poesia, e a maneira como a mesma se "forma", nos trazendo a reflexão que na poesia está expressa a individualidade de cada um. Preciosa procura essa reflexão poética para se afirmar como ela deseja ser. Alves nos dá uma visão além da poesia, mostrando que todos nós, sendo poetas ou não, somos um acumulo de acontecimentos, que podem até ser considerados insignificantes, porem são formadores potenciais das relações que vamos travar no presente e no futuro. E muitas vezes já tínhamos no passado.

Um dos espaços no qual a personagem central da trama enfrentava diversos conflitos era o espaço escolar. Lá ela sofria inúmeras agressões psicológicas e já havia reprovado inúmeras vezes. A direção da escola, infelizmente não conseguia compreender o que se passava de fato com Preciosa, pois a mesma também se fechava para o diálogo. Suas redes a formaram como uma pessoa insegura e intimidada diante de qualquer espaço que se encontrasse. Sendo assim a decisão a escola tomou foi encaminhar a aluna para uma outra instituição de ensino mais alternativa que estivesse mais apta as suas necessidades.

Figura 5 - Preciosa em sua nova sala de aula

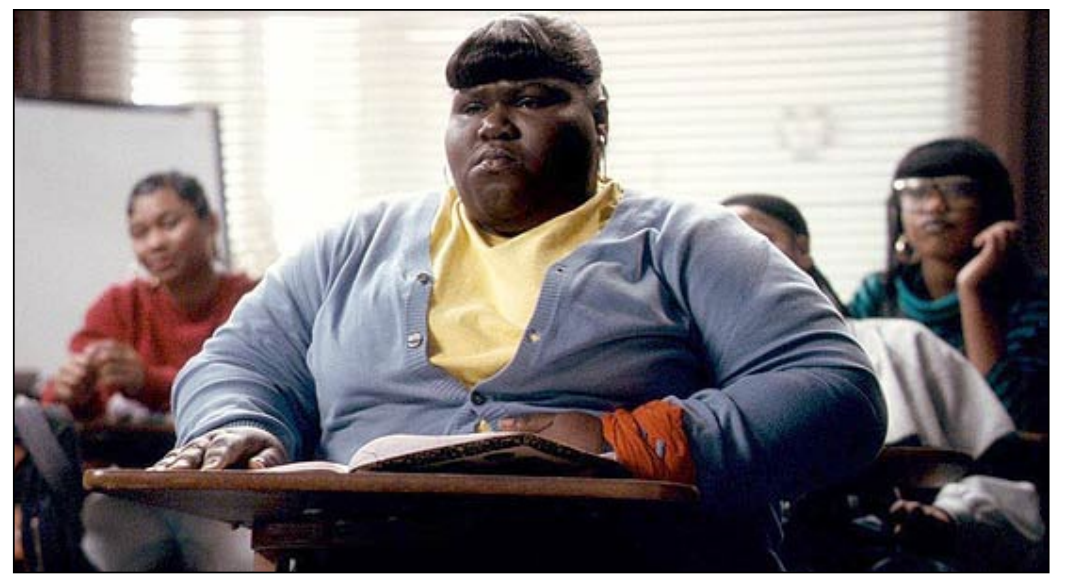

Inserida agora em um novo ambiente escolar Preciosa começa então um novo trajeto de muitas descobertas e aprendizagens, que também são frutos do trabalho da nova professora, no qual a personagem aos poucos deposita uma certa confiança. Conflitos extremos são travados durante esse momento, como por exemplo ter descoberto que foi infectada pelo vírus HIV. Porém, consideráveis conquistas também se deram neste novo contexto: a jovem que antes não conseguia enxergar e nem era motivada a ver suas qualificações, nesse momento consegue perceber seu próprio cotidiano de uma outra forma.

Ou seja, ao mesmo tempo que reproduzimos o que aprendemos com as outras gerações e com as linhas sociais determinantes do 
poder hegemônico, vamos criando, todo dia, novas formas de ser e fazer que, "mascaradas", vão se integrando aos nossos contextos e ao nosso corpo, antes de serem apropriadas e postas para consumo, ou se acumulem e mudem a sociedade em todas as suas relações. É, pois, assim que aprendemos a encontrar soluções para os problemas criados por soluções encontradas anteriormente. É preciso ter, de modo permanente, a atenção desperta, porque as tentativas de "aprisionar" este processo são violentas e moralistas, sempre. Mas o tempo todo, também, aparecem maneiras de burlar o que querem "estabelecido", "instituído" para sempre, surpreendendo até mesmo quem as empreende no que trazem de singular, e mesmo nos modos como se generalizam. (ALVES, 2003, p. 66)

Apesar de estarmos totalmente vinculados com as "linhas sociais determinantes do poder" ainda conseguimos 'espaçostempos' que são capazes de nos fazer criar novas formas de lidar com nossos atuais contextos, por mais complexos que possam ser. Foi exatamente dessa forma, que Preciosa conseguiu sobreviver diante de inúmeras problemáticas que envolviam sua história, através do processo de criação que a fez perceber formas de lidar e "trapacear" com as inúmeras injustiças que sofria e poderia sofrer, como por exemplo: a proposta de um certo "trabalho" que tinha como o objetivo a exploração física da personagem sem nenhum tipo de recompensa que a beneficiasse; a escolha de criar seus filhos frutos então de um abuso sexual; e a sua forma de aprender a lidar com uma doença que antes não fazia parte de seu trajeto, que já era por si só complexo.

Para Silvio Almeida (2018) o racismo é o suporte natural da exploração capitalista, é dentro das bases do escravismo colonialista que fundam-se as bases do sistema neoliberal que vivemos nos dias de hoje. $\mathrm{O}$ autor aponta que "o racismo seria uma espécie de resquício da escravidão, uma contaminação essencial que, especialmente nos países periféricos, impediria a modernização das economias e o aparecimento de regimes democráticos" (2018, p. 112). Desde a abolição com a transição do trabalho escravo para o trabalho assalariado corpos negros continuaram sendo explorados, pois a característica colonial do trabalho ainda manteve pessoas negras em trabalhos manuais, pesados e mal remunerado. Tanto Brasil, como os Estados Unidos de Preciosa ainda vivem reminiscência deste tipo de sistema que aprisiona, condiciona e explora pessoas negras, sobretudo mulheres. Almeida aponta que subjetivamente o racismo vai se mantendo na sociedade capitalizada como uma condição:

O racismo se manifesta no campo econômico de forma subjetiva. Como lembra Michael Reich, o racismo, de formas não propriamente econômicas, ajuda a legitimar a desigualdade, a alienação e a impotência necessárias para a estabilidade do sistema capitalista. O racismo faz com que a pobreza seja ideologicamente incorporada quase que como uma condição "biológica" de negros e indígenas, 
naturalizando a inserção no mercado de trabalho de grande parte das pessoas identificadas com estes grupos sociais com salários menores e condições de trabalho precárias (2018, p. 104).

Assim a libertação nunca pode apenas acontecer concretamente, ou no campo jurídico, é necessário que esta condição autônoma de libertação esteja associada a uma emancipação subjetiva e estética, como Preciosa busca ter. Ela precisa sim de trabalho e auxilio social, mas essa mudança precisa vir atrelado a uma mudança coletiva de consciência, onde mulheres negras e fora do padrão não sejam vistas como cidadãos inferiores na sociedade. $\mathrm{O}$ racismo não é um problema lateral da sociedade, ele só pode ser superado com uma mudança coletiva em diferentes aspectos de nossa vida social.

Preciosa pode ser inserido em uma categoria que aparece com frequência nas conversas das pesquisas com cotidianos: os filmes de escolas, professores e estudantes. Tal categoria de filmes tem muitos representantes, entre eles: Ao Mestre com Carinho (1967), Sociedade dos Poetas Mortos (1989) Escritores da Liberdade (2007), Entre os Muros da Escola (2008), A Onda (2008) e muitos outros.

A maioria destes filmes segue uma fórmula em seus enredos resumida em: um professor herói chega numa escola e pega uma turma problemática, depois de diversos atritos e dificuldades o professor inova de alguma forma e assim finalmente conquista a turma e toda a comunidade escolar, salvando o dia. Na maioria das ocasiões essa formula clichê é seguida por filmes estadunidenses.

Lembremos que esta ideia de clichê foi bem entendida no trabalho que Deleuze $(2002 ; 1985)$ realizou sobre cinema. Este autor, ao comentar nossa civilização e a ideia, vista por muitos como negativa, no que este autor não concorda, de que ela é "de imagens", escreve: "civilização da imagem? Na verdade, uma civilização do clichê" (DELEUZE, 2007). Analisando esta ideia, Guéron (2011) vai buscar compreender como o cinema, ao mesmo tempo, é criador de clichês, mas também articulador possível para se ir além deles. (ALVES, CALDAS, ROSA, 2015, p. 9)

Preciosa, é um filme potente e impactante, mas apresenta similaridades com essa estrutura clichê, porém, como vimos, o clichê é um sistema comum e recorrente em nossa forma de nos relacionarmos com o nosso ambiente. A questão não é identificá-los, reprimi-los ou reprova-los apenas, precisamos além de reconhece-los e deles fazer uso (CERTEAU, 1998).

Devemos compreender - e isto notamos, inicialmente, graças a Guéron - que embora esteja pensando cinema, Deleuze nos indica que a criação do clichê é algo fundamental à "nossa experiência cotidiana do real - constitui inevitavelmente esta - e não algo que diz respeito exclusivamente ao cinema e a outros mecanismos de 
produção das imagens" (GUÉRON, 2011, p.15). É, assim, com esta compreensão, que temos buscado dar sentido a esta adesão massiva inicial dos praticantespensantes da pesquisa aos clichês presentes nos modos como escolas, docentes e discentes são apresentados nos filmes vistos e sobre os quais "conversamos". E como, se posta uma boa questão, nessas "conversas" - como dizem Deleuze e Guattari em "O que é a filosofia?" (1992) que fazem os "personagens conceituais" aos filósofos para dar prosseguimento aos processos de pensar e criar pensamentos - se cria a possibilidade de desconstrução dos clichês. (ALVES, CALDAS, ROSA, 2015, p. 10).

Como nosso intercessor (DELEUZE, 1995) no estudo apresentado nesse texto, o enredo de Preciosa é um artefato potente para se pensar a educação e seus cotidianos escolares. Assim, vamos relacionar nossas reflexões sobre o filme com as ideias já brevemente apresentadas aqui.

\section{PERTENCIMENTO, IDENTIDADES E CURRÍCULOS NOS COTIDIANOS}

Conversando com as imagens, narrativas e sons do filme Preciosa percebemos que são as relações de pertencimento que possibilitam a reviravolta na vida da protagonista. Quando Preciosa consegue se empoderar ao ponto de se sentir dona de seu destino, mãe de seus filhos e uma escritora em potência, ela vence as dificuldades que a assolam. Este problema pode ser visto como

são manifestações práticas do cotidiano social e cultural, sinalizando uma sociedade de exclusões crescentes e explicitando, pela necessidade do pertencimento, crises e dificuldades de enraizamentos sociais e políticos, culturais e sociais: uma sociedade que convive, ao mesmo tempo, com processos de fragmentações crescentes da vida individual e coletiva e com processos políticos, econômicos e culturais (SOUSA, 2010, p. 33)

Ao se sentir pertencente a uma rede de solidariedades, tecida nos cotidianos da nova escola que passa a frequentar, Preciosa conhece verdadeiramente o afeto que a impulsiona a mudança. A diferença aqui passa então a operar não de uma forma excludente ou inferiorizada. A sua identidade como sujeito sobrepõe as dificuldades impostas pela alteridade. 
Figura 6 - Finalmente a protagonista consegue a guarda de seus filhos

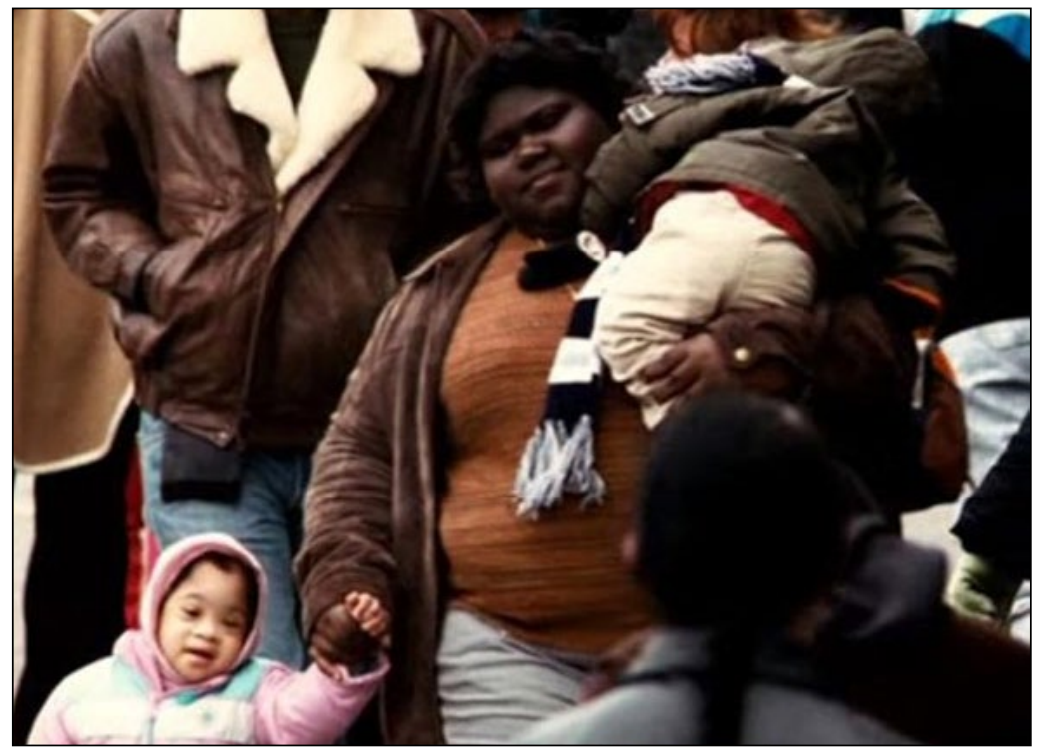

A desigualdade causada pelas ações de intolerância e preconceito às diferenças na sociedade contemporânea - considerada plural apesar de tais contradições - cria a maioria dos problemas enfrentados por Preciosa e várias outras pessoas em situações similares, principalmente as negras e marginalizadas.

Pensando no contexto que várias pessoas de descendência africana vivem, assim como Preciosa, percebemos um constante contexto de exclusão social. Porém, quase em paralelo, as culturas da diáspora negra produziram diversas manifestações culturais, desde o balanço na música, o sincretismo na religião e as artimanhas para o trabalho. Todas estas expressões são marcas da identidade coletiva da diáspora negra que promove uma subversão rizomática dos sistemas centralizadores. Longe de ser única e essencializada, essa forma de identificação (pertencimento) é ampla, como afirma Hall: "na situação da diáspora, as identidades se tornam múltiplas" (HALL, 2003, p. 27), e aqui). Aqui o múltiplo não aparece como algo disperso e divergente, mas sim como uma força contra hegemônica. A diferenciação é o que possibilita a criação de táticas cotidianas para a virada do tabuleiro.

O Outro é o que tem outros valores, crenças, hábitos e saberes. É aquele ou aquilo que emerge com as crises do crível e engendra credibilidades nascentes, que não se possui nem se controla. $\mathrm{O}$ Outro é o que escapa. É o imprevisível, o inesperado, o excluído, o imigrante, o marginalizado, o estrangeiro, o que nos antecedeu e, ainda, o que virá depois de nós. É mistério e surpresa. É a alteridade 
radical, a diferença para a qual nós precisamos nos abrir para inventar o novo. (ALVES, FERRAÇO e SOARES, 2017, p. 10)

Apesar do clichê no discurso de dificuldade seguida de superação das dificuldades, se deparar com narrativas que sirvam como exemplo e inspiração nos contemplam ao pensar no questionamento das próprias desigualdades vividas pela população brasileira, principalmente sua parcela negra. Desta forma, uma narrativa como Preciosa nos auxilia na possibilidade de "reescrever a história das insurgentes culturas negras brasileiras, suas batalhas contra a escravidão e as extensas contribuições as culturas translocais de oposição a engrenagem da hierarquia racial" (GILROY, 2001, p. 14).

As imagens, narrativas e sons do cinema "tem se mostrado extremamente interessantes como possibilidades menos estruturadas e formal de problematização dos cotidianos escolares "(ALVES, FERRAÇO, 2015, p. 312). É aí onde se está presente a potência do ato de ver, ouvir, sentir um artefato cultural para os cotidianos escolares, estes aparecem "como alternativa mais potente para o entendimento dos processos de invenção/resistência que são vividos na complexidade das redes tecidas pelos praticantes dos cotidianos escolares" (Ibidem).

Os mundos culturais dos 'praticantespensantes' dos cotidianos escolares são tecidos em redes educativas que rompem com as dicotomias e hegemonias da ciência moderna.

Ao pensar "a cultura" como uma rede de operações produtoras de saberesfazeres, poderes e significados, Certeau (1995) descolou a compreensão de ação cultural ou política como algo realizado de forma centralizada e de cima para baixo para algo tecido permanentemente nas/com as práticas sociais cotidianas que produzem significados para aqueles que as realizam. (ALVES, FERRAÇO e SOARES, 2017, p. 13)

Assim, os acontecimentos dos cotidianos escolares, apesar de cerceados por hegemonias curriculares, como a Base Nacional Comum Curricular ${ }^{4}$ ou a Lei $10.639 / 03^{5}$, criam currículos cotidianamente, aliando-se a estas legislaturas ou não. A criação de currículos nos cotidianos escolares acontece com o ato da

4 A BNCC vem como uma proposta "milagrosa" para "salvar" a educação de sua precariedade. Controversamente a proposta incentiva parcerias público-privadas, apostilamento da educação e distanciamento a causas sociais como a diversidade cultural e religiosa, e a questão de gênero. Uma tentativa neoliberal para salvar os professores da própria ineficiência (ALVES, CALDAS e ROSA, 2015)

5 Lei que institucionaliza a inserção das culturas e histórias africanas e afrobrasileiras nos currículos da educação básica brasileira (BRASIL, 2003). 
tessitura das diferentes redes de 'conhecimentossignificações' que estão presentes neles. Assim,

essas considerações nos permitem ver, complexamente, os processos de centralização dos currículos e as influências possíveis na formação docente: se por um lado, percebemos os movimentos de centralização curricular que, oficial e mundialmente, vão se agudizando no presente, por outrolado, entendemos que estes processos têm a ver com articulações múltiplas nas/das/com as diversas redes educativas que formamos e que nos formam a todos, nos cotidianos. Mais do que isto, como pesquisadoras com os cotidianos, vamos buscando compreender como nos indicou Certeau (1994) que, apesar de todas as determinações oficiais centralizadoras e de manipulações sem fim nas mídias, nenhuma sociedade cai toda ela subjugada às determinações hegemônicas. (ALVES, CALDAS, ROSA, 2015, p. 5)

\section{CONSIDERAÇÕES FINAIS}

O cinema e todas as potencialidades que o compõe são fortes artefatos culturais para o questionamento da realidade que vivemos. Não deixando de se ater a seu caráter de criação humana, influenciado no seu processo de produção por diversos fatores e acontecimentos externos, não reproduzindo somente um mero simulacro da realidade. O filme Preciosa, Uma História de Esperança (2009), com sua narrativa de superação e descobrimento da poderosa protagonista nos possibilitou a pensar em quantas outras pessoas não estiveram em situações parecidas com a retratada no filme. Podemos questionar também a forma como a educação pode causar a mudança numa sensação de pertencimento com pessoas que precisam de afeto e auto estima para enfrentar seus problemas.

A luta das populações afrodescendentes na diáspora negra por toda a América e até no continente africano tenta superar o histórico de dificuldades e opressões. Este é um processo árduo e complexo, mas se inspirando em imagens, narrativas e sons que possibilitem uma fagulha de mudança é o que nos faz acreditar na possibilidade de cisão com este paradigma.

Os cotidianos escolares são as maiores potências para promover tais mudanças, apesar da reconhecida dificuldade da educação brasileira, encontramos diversos exemplos, práticas, táticas e artimanhas que conseguem ludibriar as dificuldades impostas. Nos inspirando naqueles que resistem e criar formas de subversão as desigualdades vamos caminhando em busca de um futuro mais justo. 


\section{REFERÊNCIAS}

ALMEIDA, Silvio. O que é racismo estrutural? Belo Horizonte: Letramento, 2018.

ALVES, Nilda. Decifrando o pergaminho - o cotidiano das escolas nas lógicas das redes cotidianas. In: OLIVEIRA, Ines Barbosa de; ALVES, Nilda. (Org.). Pesquisa no/ do cotidiano das escolas: sobre redes de saberes. Rio de Janeiro: DP\&A, 2001.

ALVES, Nilda. Redes educativas, fluxos culturais e trabalho docente - o caso do cinema, suas imagens e sons. Rio de Janeiro: ProPEd/UERJ, 2011. (Projeto de pesquisa, entre 2012 e 2017; financiamento: UERJ, FAPERJ, CNPq).

ALVES, Nilda. Cultura e cotidiano escolar. Revista Brasileira de Educação, n.23, pp.6274. 2003.

ALVES, Nilda; FERRAÇO, Carlos Eduardo; SOARES, Maria da Conceição.Michel de Certeau e as pesquisas nos/dos/com os cotidianos em educação no Brasil. Pedagogía y Saberes No. 46 Universidad Pedagógica Nacional Facultad de Educación. 2017, pp. 7-17

ALVES, Nilda; CALDAS, Alessandra Nunes; ROSA, Rebeca Brandão. Formação de professores com filmes: os clichês como formadores de docentes. S. Paulo: PUC-S. Paulo/Programa de Pós-graduação em Educação-Currículo. Revista e-Curriculum. Dossiê ABdC - "Formação Docente frente às políticas no cenário de centralização curricular", vol 13, n. 4, out-dez 2015: 775-793.

ALVES, Nilda; FERRAÇO, Carlos Eduardo. AS PESQUISAS COM OS COTIDIANOS DAS ESCOLAS: pistas para se pensar a potência das imagensnarrativas na invenção dos currículos e da formação. ESPAÇO DO CURRÍCULO, v.8, n.3, p. 306-316, setembro a dezembro de 2015

BRASIL. Ministério da Educação. Lei n. 10.639, de 9 de janeiro de 2003. Altera a Lei n. 9.394, de 20 de dezembro de 1996, que estabelece as diretrizes e bases da educação nacional, para incluir no currículo oficial da Rede de Ensino a obrigatoriedade da temática "História e Cultura Afro-Brasileira", e dá outras providências. Diário Oficial da União, Brasília, 10 jan. 2003.

BRASIL. Lei 13.006, de 26 de junho de 2014, acrescenta § 8o ao art. 26 da Lei no 9.394, de 20 de dezembro de 1996, que estabelece as diretrizes e bases da educação nacional, para obrigar a exibição de filmes de produção nacional nas escolas de educação básica. Diário Oficial da União, Brasília, 25 jun. 2014.

CARVALHO, Noel dos Santos. Esboço para uma história do negro no cinema brasileiro. In: Jeferson De. (Org.). Dogma Feijoada o Cinema Negro brasileiro. São Paulo: Imprensa Oficial, 2005, v. 1, p. 17-101.

CERTEAU, Michel de. A invenção do cotidiano - artes de fazer - $3^{\mathrm{a}}$ ed., Vol.1. Petrópolis: Vozes, 1998. 
DELEUZE, Gilles; Guattari, Felix. 1. Introdução: rizoma. Mil platôs - capitalismo e esquisofrenia - vol. 1. Rio de Janeiro: Ed. 34, 1995: 10 - 36.

DELEUZE, Gilles; GUATTARI, Félix. Personagens conceituais. In: DELEUZE, Gilles; GUATTARI, Félix. O que é filosofia? Rio de Janeiro: Editora 34, 1992. p. 81 - 109.

GOMES, Nilma Lino. Alguns termos e conceitos presentes no debate sobre relações raciais no Brasil: uma breve discussão. In: BRASIL. Educação anti-racista: caminhos abertos pela Lei Federal n. 10.639/03. Brasília: MEC/SECAD, 2005.

GILROY, Paul. O Atlântico Negro. Modernidade e dupla consciência, São Paulo, Rio de Janeiro, 34/Universidade Cândido Mendes - Centro de Estudos Afro-Asiáticos, 2001.

GUERÓN, Rodrigo. Da imagem ao clichê, do clichê à imagem: Deleuze, cinema e pensamento. Rio de Janeiro: NAU editora, 2011.

HALL, Stuart. Da diáspora: Identidades e mediações culturais. Org. Liv Sovik; Adelaine La Guardia Resende et al. (trad.) Belo Horizonte: Editora UFMG, 2003.

NOGUERA, Renato. Denegrindo a Filosofia: o pensamento como coreografia. Griot, v. 4 n.2, p.1-19. dezembro. 2011. Disponível em: <http://www.academia.edu/24801938> Acesso em: 19 Jul 2017

OLIVEIRA, Inês Barbosa de. Currículos e pesquisas com os cotidianos: o caráter emancipatório dos currículos 'pensadospraticados' pelos 'praticantespensantes' dos cotidianos das escolas. In: Carlos Eduardo Ferraço e Janete Magalhães Carvalho (Org.). Currículos, pesquisas, conhecimentos e produção de subjetividades. 1. ed. Petrópolis: DP et Alli, 2012, p. 47-70.

OLIVEIRA, Janaína. Kbela e Cinzas: O cinema negro no feminino do 'Dogma Feijoada' aos dias de hoje. In: Avanca Cinema: Conferência Internacional, 2016.

RODRIGUES, José Carlos. O Negro Brasileiro e o Cinema. 3. ed: Pallas, 2011.

SODRÉ, Muniz. Reinventando a educação: diversidade, descolonização e redes. Petrópolis: Vozes, 2012.

SOUSA, Mauro Wilton. O pertencimento ao comum mediático: a identidade em tempos de transição. Revista Significação. n³4. 2010.

SOUZA, Edileuza Penha de. Cinema na panela de barro: mulheres negras, narrativas de amor, afeto e identidade. Tese (doutorado). Universidade de Brasília, Programa de Pós-graduação em Educação. 2013.

XAVIER, Giovana. Segredos de penteadeira: conversas transnacionais sobre raça, beleza e cidadania na imprensa negra pós-abolição do Brasil e dos EUA. Estudos Históricos (Rio de Janeiro) [online]. v. 26, n. 52. 2013. 